\title{
First do no harm: Teaching and assessing the recognition and rescue of deteriorating patients to nursing students
}

\author{
Guy Tucker, John Unsworth *'Yvonne Hindmarsh \\ Department of Healthcare, Northumbria University, Newcastle, United Kingdom
}

Received: October 6, 2014

DOI: $10.5430 /$ jnep.v5n6p31

\author{
Accepted: March 15, 2015 \\ Online Published: March 27, 2015 \\ URL: http://dx.doi.org/10.5430/jnep.v5n6p31
}

\begin{abstract}
Failure to recognise and appropriately rescue the deteriorating patient is a global issue which has the potential to cause serious harm to patients. Such recognition and rescue of a deteriorating patient requires both technical and non-technical skills and there are multiple points for potential failure. The taking and recording of vital observations is one of the cornerstones of recognising deterioration. However, such observations are often delegated to students and the least experienced staff. This paper explores the teaching and assessment of under-graduate nursing students to recognise and arrange the rescue of a deteriorating patient within the first 16 weeks of their course. The paper describes the development of an integrated Objective Structured Clinical Examination (OSCE) and the subsequent evaluation of this using survey data, student performance results and unobtrusive methods. The results suggest that it is possible to use an integrated OSCE to assess students even at such an early stage in their course. Although data from other Higher Education Institutions in the UK suggests that integrated OSCEs at such an early stage are rare. The appropriate teaching of vital observations, structured hand off and reporting enable students to contribute to safer care and to adhere to the maxim "First Do No Harm".
\end{abstract}

Key Words: Deterioration, Observations, Objective structured clinical examination, Assessment

\section{INTRODUCTION}

Primum non nocere "First do no harm" is a fundamental maxim of medical practice and a key element of the Hippocratic oath. ${ }^{[1]}$ The maxim is also true of nursing with Florence Nightingale identifying more than 150 years ago that the hospital should do the sick no harm. ${ }^{[2]}$ Increasing acuity of hospital in-patients and the 24 hour nature of the nursing presence means that nurses need to be constantly vigilant to ensure that patients are cared for in a safe and effective way. Failure to recognise and organise appropriate rescue of the deteriorating patient is recognised as a global issue. ${ }^{[3,4]}$ In part the problem of a failure to rescue arises from the increasing acuity of patients on general wards, the fact that certain aspects of practice, including the measurement of vital observations, has become routinized ${ }^{[5]}$ and the fact that the measurement of vital observations is often delegated to the least qualified and inexperienced members of the nursing team. ${ }^{[6]}$ Failure to rescue the deteriorating patient is a complex and multi-faceted problem with multiple potential points for failure ${ }^{[7]}$ arising from both technical skills in vital observation measurement and patient assessment and from non-technical skills such as communication, situational awareness and clinical decision making. Across the globe healthcare systems have implemented a number

\footnotetext{
*Correspondence: John Unsworth; Email: john.unsworth@northumbria.ac.uk; Address: Department of Healthcare, Northumbria University, Newcastle-upon-Tyne, United Kingdom.
} 
of interventions designed to reduce the likelihood of failure in terms of the recognition and rescue of the deteriorating patient. Such systems include the implementation of physiological track and trigger systems or early warning scores, ${ }^{[8]}$ staff training and support and systems which are designed to support non-technical skills such as Situation, Background, Assessment and Recommendation mnemonic (SBAR) for structured communication between health professionals. ${ }^{[9]}$

While a considerable amount of work has been done to address concerns about failure to rescue student nurses on work placements remain a potential weak link in the system because they are often not included in work based training and staff development programmes offered to permanent registered nurses. In addition, student nurses are often delegated tasks such as the measurement of a patient's vital signs. Most nurse education providers have kept pace with the developments around the introduction of early warning scores and the use of SBAR for structured communication and these are now integrated into nursing curricula. However, the use of practical assessment of performance in these areas is less commonplace. Merriaman and Westcott ${ }^{[10]}$ describe how the use of the Objective Structured Clinical Examination (OSCE) is becoming increasingly commonplace in nursing curricula. First developed in 1975 OSCEs have been widely used in medical education. ${ }^{[11]}$ An OSCE involves rotating students through a number of stations which simulate a clinical reality. At each station the student is expected to perform a skill on a standardised patient, task trainer or mannequin. ${ }^{[10]} \mathrm{A}$ common feature of an OSCE examination is that the student moves between stations with each stations being assessed by a different examiner over a defined period. Each station has a set structure to ensure that the examination is consistent between candidates. In medical education it is common to have OSCE examinations which relate to individual system assessment and conditions. In nursing, OSCE assessments have been used to assess competence in the performance of different psychomotor skills such a blood pressure measurement, urinalysis etc. or to assess the students ability to perform and assessment of a patient. Some nursing OSCEs are integrated in nature that is that they require the student to undertake an assessment and organise interventions for a single patient with each aspect of the examination forming a different timed station.

Recognising the need to ensure that under-graduate nurses are adequately prepared for their first practice experience and to ensure that they have the necessary knowledge and skills to appropriately assess, recognise and organise the rescue of a deteriorating patient the team set out exploring the use of an OSCE. This OSCE focused on the assessment and rescue of a deteriorating patient would be particularly chal- lenging as under-graduate nurses would be expected to pass the assessment within the first 16-18 weeks of their nursing programme. The aims of the project were to:

(1) Identify whether other Higher Education Institutions in the United Kingdom were using OSCE assessments early in their curriculum;

(2) Develop an OSCE assessment related to recognition and rescue of the deteriorating patient which was broadly similar across all of the UK fields of nursing practice;

(3) Analyse student performance in terms of the OSCE assessment and adjust the teaching and/or assessment to ensure that students felt supported and adequately prepared;

(4) Identify student's knowledge, beliefs and what opportunities they had to practice their skills both prior to and after the OSCE assessment.

\section{OSCE assessment design}

The OSCE was developed in partnership with clinical practitioners, it was recognised that patient safety is of paramount importance given the identified possible impact upon patient mortality, morbidity and quality of life. ${ }^{[12]}$ An OSCE or Objective Structured Clinical Examination was originally developed as a way of assessing clinical skills by Harden and Gleeson in 1975. ${ }^{[13]}$ Since its initial development it has been used as a reliable method of assessing and evaluating student performance assessing a single or range of skills is based on objective testing through direct observation. This normally occurs in a formal setting, in a given time and assessment is made using performance criteria, which has been devised to the skill or attitude being tested. ${ }^{[14]}$

Prior to the OSCE the students are introduced to paper based scenarios to enable them to contextualise the patient's presentation. In developing the OSCE scenarios the team were mindful of the need to ensure that the assessment was both meaningful and authentic. Mueller ${ }^{[15]}$ identifies how an authentic assessment should require a student to perform a meaningful task which replicates the challenges from the "real world".

At each station the students' performance was rated by one examiner using a checklist. The checklists required the assessors to identify each element from a list as either "pass" or "fail". The examiners were trained in the use of the checklist. The responses of the student were measured against agreed criteria developed by the team. The use of highlighted compulsory elements of the assessment was adopted to emphasise the clinical importance of these elements. Omission of these safety related measures (e.g., decontamination of equipment 
or hands) would lead to an automatic fail irrespective of the overall assessment outcome. The utilisation of both high and low fidelity mannequins allows the students to witness a physiological response and undertake the measurement of the patients vital observations including temperature, heart rate, respiratory rate, capillary refill, $\mathrm{Sp}_{2}$, manual blood pressure thereby reinforcing the authentic nature of the assessment. ${ }^{[15]}$

The aim of the assessment is for the student to demonstrate that they can identify a deteriorating patient, undertake and record the appropriate vital observations and correctly report their results. The entire OSCE assessment takes 30 minutes to complete the students spend 10 minutes at each station.

The students are awarded a pass/fail grade based on the demonstrating of specific performance criteria. A pass/fail system was preferred over a percentage pass mark because the team quickly identified that students could attain a pass mark $(40 \%)$ while still missing essential elements of the assessment thereby placing patient at risk of harm.

The OSCE consists of 3 OSCE stations which are:

- Station 1 - Practical application of a chosen skill i.e., Measuring Vital Observations

- Station 2 - Communication - of results/findings from Station 1 using the SBAR tool (Situation Background, Assessment Recommendations).

- Station 3 - Record keeping - Documenting information relevant from stations 1 and 2 .

Prior to the OSCE assessment a range of teaching strategies were used to address different learning styles. Bloom's taxonomy of learning acknowledges that by attempting to address different learning domains rather than just verbal recall of information, deeper learning may be achieved which may address the cognitive, psychomotor and affective domains. ${ }^{[16]}$ Teaching strategies therefore addressed the cognitive domain by using lectures on vital observations and the use of physiological track and trigger systems (early warning scores). The psychomotor domain was addressed using skills based practical sessions which included demonstrations on how to conduct vital observations as well as time for the students to practice and gain feedback on their performance. Affective methods addressed issues of patient safety and, professional role requirements to ensure other strategies were contextualised as well as addressing student anxiety about the OSCE assessment and technical nursing skills development.

As part of the process for supporting students, a Student Resource Pack was produced to facilitate student learning and understanding in relation to vital observations. Evidence has demonstrated that students learn via many different methods, this is often depending on what type of learner they are

Published by Sciedu Press e.g., their learning style. This was part of the rationale behind providing information by addressing Activist, Reflector, Pragmatic and Theorist styles to enhance knowledge. ${ }^{[17]}$

Professional regulatory requirements require that practitioners to have a robust knowledge base. Greenhalgh and Donald ${ }^{[18]}$ state that this ensures the effectiveness of resource allocation, patient safety and decision making based on best available evidence. In order to develop the student's knowledge base for practice information was presented in both a visual and a step-by-step approach to aid memory storage and retrieval. Such an approach supports cognitive load theory. ${ }^{[19]}$ Which Artino ${ }^{[20]}$ observes is necessary as an individual's working memory has limited space, whilst long term memory has space for potentially unlimited information, if instructional material is too complex it will hinder working memory and cognitive learning. Part of the instructional sessions involved students having the opportunity to practice their verbal communication skills using a recognised structured method of handing off (SBAR). This was incorporated into a role play. Kesten ${ }^{[21]}$ identifies how the SBAR structure can be useful during role play if being used by student nurses, as it facilitates a structured method of delivering relevant patient information in a quick and logical manner.

Lewin ${ }^{[22]}$ proposed that change requires driving forces for the change to overcome resisting forces and that the success of any change rests on many different factors including the roles of both early adopters and resisters. Some staff indicted that this method of teaching support and assessment would be "too difficult to do" given the student numbers and the early stage of the student's programme of study. However, the overarching driving force of ensuring and promoting patient safety provided a common ethos for the proposed change. In addition, concerns about how these skills had been taught historically and the "drivers" for change based on literature and data linked to patient safety ${ }^{[7]}$ and $^{[8]}$ also assisted in convincing Faculty of the need for change. Lewin ${ }^{[22]}$ describes laggards as, those whose resistance is born from fear of change and lack of knowledge or skills. In relation to the OSCE assessment method, staff feared the unknown, in terms of a new method of assessment and whether true objectivity was possible. To negate this staff training events, based on a "walk-through" of each OSCE assessment station together with questions and answers sessions and comprehensive OSCE facilitator's guides further supported staff.

\section{METHOD}

The evaluation study utilized secondary data, a selfcompleted survey and unobtrusive methods to collect data about performance, the use of OSCEs by nurse education providers and to explore student's knowledge and percep- 
tions. A short self-completed survey was provided to all students who agreed to participate in the evaluation. The survey consisted of demographic data exploring the participants age, gender and previous healthcare experience as well as a series of questions utilising Likert scale and true and false responses to a range of statements. In addition, the survey explored what opportunities students had to practice their skills both within University and in the clinical setting both prior to and after their OSCE assessment.

Surveys are instruments which usually consist of a series of questions and/or statements which elicit responses from research subjects. ${ }^{[23]}$ Most surveys are quick to complete, relatively inexpensive to administer and can be distributed to relatively large samples. The disadvantages of surveys include issues around response bias and unreliability of the responses. ${ }^{[24]}$

The self-completed survey was distributed to 325 undergraduate nursing students who were at the end of their first year of their studies. They had all had theoretical and practical instruction about all aspects of the OSCE assessment and had been afforded the opportunity to practice these skills in University and in clinical practice prior to undertaking their OSCE examination.

Secondary data took the form of assessment performance in terms of the number of students passing and failing each station of the assessment at the first attempt and the number of students who successfully completed the assessment at the second (final) attempt. The use of secondary data is not without its challenges as the data was not originally collected for the purpose for which it has been subsequently used e.g., in research. In addition, it is difficult to return to the original sample for clarification on issues which arise from the data. This can lead to misinterpretation of the data and to concerns about the ethics of using data where the participants did not realise that it would be processed for that purpose. ${ }^{[25]}$

Unobtrusive methods were used to collect data from Higher Education Institutions which offer nursing programmes within the United Kingdom. Unobtrusive methods are described as methods where "data is gathered by means that do not involve direct elicitation of information from research subjects". ${ }^{26]}$ Such methods have strengths and weaknesses with a key strength being that they are inexpensive to administer, at least for the researcher. Weaknesses include misrepresentation of the data because of unclear requests or to show an organisation in a more favourable light. Unobtrusive methods have been used in healthcare research by either requesting specific information or by accessing secondary data sources such as minutes of meetings. ${ }^{[27,28]}$ One form of unobtrusive method is the use of Freedom of Information Act
(2000) requests to public organisations. Within the United Kingdom the Freedom of Information Act (2000) requires public bodies to make available on request or in advance by via publication scheme specific information about their activities. ${ }^{[29]}$

The research team made written request to 43 nurse education providers (Universities) in the UK to request the following data:

(1) Whether OSCE (Objective Structured Clinical Examination) is used as a method of assessment at any stage within the nursing programme(s)/course?

(2) At what stage of the course is the OSCE assessment used e.g., programme year or academic level?

(3) How many OSCE stations are used in each assessment?

(4) Please provide brief details of each station which makes up the assessment e.g., drug administration, aseptic technique, blood pressure etc.

Data from secondary sources were analysed by counting to produce total numbers of successful and unsuccessful students, mean averages and percentages. Data from surveys were coded and then analysed to produce descriptive statistics. The data from the unobtrusive methods were analysed by coding the responses into categories e.g., type of OSCE assessments used by academic year and then to produce descriptive statistics.

\section{RESULTS}

\subsection{Use of OSCE assessments in nursing across UK higher education}

Freedom of Information Act requests were sent to 43 Higher Education Institutions in the UK. Of these 40 responded giving a response rate of $93 \%$. Of the 40 responses a total of 9 Institutions report that OSCE was not used at all in their under-graduate curriculum with a total of 31 Institutions reporting some OSCE based assessment.

Of the 31 Institutions who used OSCE assessments the majority $(n=19,61 \%)$ used a single OSCE in a single year of the programme. Only 7 Institutions (22\%) used OSCE in two different years of the programme and 5 (16\%) used OSCE as a method of assessment in all three years of the programme. A total of 5 Institutions undertook OSCE assessments in years one and two of the programme and 2 Institutions used such assessments in year one and the year three of the programme.

The mean average number of stations for each OSCE assessment was 4 in year one, 2.5 in year two and 2 in year three. The types of stations are described in Table 1. 
Table 1. Types of nursing OSCE station assessments used by UK higher education institutions

\begin{tabular}{ll}
\hline Year & OSCE Station Themes \\
\hline & Aseptic technique \\
& Taking a catheter specimen of urine \\
& Manual blood pressure recording \\
& Vital observations \\
One & Calculating an early warning score \\
& Moving and handling \\
& Hand washing \\
& ABCDE rapid patient assessment \\
& Basic life support \\
& Medication administration \\
Two & Teaching a patient about their medications \\
& First aid \\
& Vital observations \\
& Simulation scenario based integrated assessment, management and decision making \\
& SBAR handover \\
Three & Patient assessment skills \\
&
\end{tabular}

Of the Institutions using OSCE in year three only, 9 used simulation based integrated OSCEs designed to assess the student's abilities in patient assessment, management and clinical decision making. Only 1 Institution used an integrated approach to OSCE around patient deterioration in the first year of the programme. This was similar in approach to the OSCE described in this paper.

\subsection{Initial OSCE performance}

The data about OSCE pass rates identified some interesting themes. Station one on both the September and March cohorts carried the greatest percentages of refers. The main fail area was pulse or blood pressure measurement and decontamination of either the student's hands or the equipment ( $\mathrm{n}$ [57] $=19 \%$ Station One fails for the September cohort and $n$ [23] $=11 \%$ Station One fails in the March cohort). The results highlighted that Station two carried the lowest percentage of referrals (n [0] $=0 \%$ for September and $n[3]=8 \%$ for March cohorts) in both cohorts. The main problem area in Station three identified that students were failing to record a signature, print their name and write their designation in the records despite this being a requirement for the regulators standards for records and record keeping. ${ }^{[30]}$ All students who were referred subsequently passed at resit examination.

Table 2. Post OSCE student survey results

\begin{tabular}{|c|c|c|}
\hline \multicolumn{3}{|l|}{ Opportunity to Practice Blood Pressure Prior to the OSCE Assessment* } \\
\hline & $\mathbf{n}$ & Percentage \\
\hline At University on other students & 87 & $34.8 \%$ \\
\hline At University on a mannequin & 221 & $88.4 \%$ \\
\hline On placement on a patient & 90 & $36 \%$ \\
\hline On placement on other students & 87 & $34.8 \%$ \\
\hline On placement on staff & 86 & $34.4 \%$ \\
\hline At home on friends and family & 68 & $27.7 \%$ \\
\hline Yes & 130 & $52 \%$ \\
\hline No & 120 & $48 \%$ \\
\hline \multicolumn{3}{|c|}{ Student who had recorded a manual blood pressure reported the following circumstances** } \\
\hline Routinely on placement & 46 & $35 \%$ \\
\hline Automated blood pressure machine could not record/inaccurate reading & 16 & $12 \%$ \\
\hline For accuracy in certain patient conditions & 6 & $4 \%$ \\
\hline On friends and family & 10 & $7 \%$ \\
\hline Taking and recording of vital observations & 249 & $99.6 \%$ \\
\hline Calculation of an Early Warning Score & 242 & $96.8 \%$ \\
\hline Identification of a deteriorating patient & 243 & $97.2 \%$ \\
\hline Handover to other staff using SBAR & 243 & $97.2 \%$ \\
\hline Record keeping & 249 & $99.6 \%$ \\
\hline Care of a deteriorating patient & 232 & $92.8 \%$ \\
\hline
\end{tabular}

*Students could select more than one category; ** Not every student provided the circumstances.

\subsection{Student survey results}

A self-completed survey was distributed to 325 undergraduate students once they had completed their OSCE as-

Published by Sciedu Press sessment. A total of 250 surveys were completed representing a $76.9 \%$ response rate. Table 2 details the results of the survey. From this table it can be seen that the majority of 
students had an opportunity to practice manual blood pressure and vital observation measurement on a mannequin, fellow students, staff or on placement with patients prior to undertaking their OSCE assessment.

Some $48 \%$ of students $(n=120)$ had undertaken a manual blood pressure since completion of the OSCE most frequently because this was part of the routine during the placement or because of automated machines being unable to accurately record a blood pressure. The range of skills assessed during the OSCE had been used by almost all students in clinical practice since the assessment.

During the survey student's level of knowledge about manual blood pressure and their perceptions of its importance were tested using true and false statements and a series of Likert scales where students were asked to rate statements. The results of this are set out in Table 3 . The results show that the majority of students were aware that manual (auscultation of) blood pressure was more accurate than that recorded by an oscillometric device (automated blood pressure machine). However, a number of students $(n=55,23.1 \%)$ did not know that oscillometric devices detect arterial wall movement.

The majority of students understood the importance of manual blood pressure auscultation in recognising patient deterioration but still believed that automated machines had rendered auscultatory methods virtually obsolete.

Table 3. Knowledge about and perceptions of the recording of manual blood pressure

\begin{tabular}{|c|c|c|c|c|c|c|c|}
\hline \multicolumn{8}{|l|}{ True/False statements used to test student's knowledge } \\
\hline Statement answer & Correct & \multicolumn{2}{|l|}{ True n } & \multicolumn{2}{|l|}{$\%$} & False n & $\%$ \\
\hline Automatic blood pressure recording is more accurate than manual recording & False & 228 & & 92 & & 20 & 8 \\
\hline Atherosclerosis may make automatic blood pressure recordings incorrect & True & 194 & & 83 & & 40 & 17 \\
\hline Manual blood pressure recording is more accurate in hypotension & True & 208 & & 87 & & 32 & 13 \\
\hline Automatic blood pressure machines detect arterial wall movement & True & 55 & & 23 & & 183 & 77 \\
\hline \multicolumn{8}{|l|}{ Statements about student perceptions } \\
\hline Manual blood pressure is a skill needed by all registered nurses & \multicolumn{2}{|l|}{6} & \multicolumn{2}{|l|}{4} & \multicolumn{2}{|l|}{55} & 181 \\
\hline Technology had made manual recording of blood pressure obsolete & \multicolumn{2}{|l|}{32} & \multicolumn{2}{|l|}{85} & \multicolumn{2}{|l|}{103} & 24 \\
\hline Manual blood pressure is important in the recognition of patient deterioration & \multicolumn{2}{|l|}{4} & \multicolumn{2}{|l|}{27} & \multicolumn{2}{|l|}{115} & 99 \\
\hline Manual blood pressure is outdated and no longer routinely practiced & \multicolumn{2}{|l|}{66} & \multicolumn{2}{|l|}{125} & \multicolumn{2}{|l|}{43} & 10 \\
\hline
\end{tabular}

\section{Discussion}

In developing the OSCE the programme team were confident that some form of assessment was needed to safeguard patients from harm as a result of failure to rescue and appropriately respond to deterioration. What was unclear during the development of the OSCE was whether such an assessment so early in the programme would lead to a high failure rate and whether the expectations were set too high. The results of the first two cohorts reveal that such concerns were unfounded and that the failure rate was no higher in this module of the programme than for any other form of assessment.

The survey using unobtrusive methods of other Higher Education Institutions in the UK reveals that the use of integrated OSCE assessments are relatively rare and that only one other example of the use of such an assessment was found in the first year of a nursing course.

The development of the OSCE has resulted in a number of 'spin-offs' both within practice settings and amongst the student population. Firstly, practitioners in partner National Health Service (NHS) organisations are becoming increasingly aware of their own practice around vital observation measurement. A number of NHS organisations have ordered new aneroid sphygmomanometers and have started to train their own qualified staff in manual blood pressure measurement. Secondly, the student population have identified gaps in the availability of equipment and in the skills of their practice based mentors in NHS organisations. There have been anecdotal reports from students where medical staff have requested that qualified staff manually measure a patient's blood pressure where student nurses have stepped forward as the only member of a ward team who can accurately take and record such an observation. Finally, as the students have progressed through the programme academic staff have noticed that they have increased confidence in the taking of vital observations, handover and responding to medical emergencies when compared with students who had undertaken previous courses.

The student survey results also suggest the importance of the skills assessed through the OSCE with just under half of the students having performed a manual blood pressure since the OSCE within the practice setting. Furthermore, almost all of the students had used the skills taught during 
the module and assessed via the OSCE such a recognising deterioration in patients, SBAR based handovers and vital observation measurement within the practice setting.

The survey also revealed that whilst there were gaps in the student's knowledge the majority understood the importance of vital observation measurement and in particular the need for skills in manual blood pressure monitoring. In response to the survey feedback the module team developed the taught content to re-emphasise key messages. A greater emphasis was placed on how all of the equipment works and what is occurring when for example oscillometric devices are places on the patient's arm. Further visual materials were developed for example video clips and posters. The clinical skills centre was enhanced to accommodate equipment to enable students to practice at times which suited their independent study time.

While the OSCE assessment occurs early in the programme the spiral nature of the under-graduate nursing programme means that topics are iteratively revisited at various points. One area which is extensively revisited and built upon is the recognition and rescue of the deteriorating patient with further lectures, seminars and simulation practical's relevant to this topic area being delivered in years 2 and 3 of the programme. Students get the opportunity to undertake high fidelity simulation sessions with structured de-brief around recognising hypovolaemic shock, dealing with exacerbations of long term conditions and acute medical emergencies during the course. This allows the students to build on the knowledge and skills they have developed earlier in the programme and apply these in conditions specific scenarios.

The evaluation of the OSCE has provided some insight into the success of the assessment, how common such assessment methods are and some evidence about student's perceptions and knowledge. Further research work needs to be undertaken to explore how the OSCE assists students to develop their confidence and competence in relation to the recognition and rescue of the deteriorating patient.

\section{Conclusion}

This paper has outlined how it is possible to both teach and assess the skills needed to ensure recognition and rescue of the deteriorating patient early in their under-graduate programme. The development and successful implementation of an integrated OSCE assessing 350 students in a single week highlights that it is possible to use such methods even with large cohorts of students. Those students who have successfully completed the taught module and the assessment are now well equipment with the knowledge and skills both to record vital observations but also to take appropriate action if they notice that the parameters are not normal. The initial teaching in this area is reinforced throughout the curriculum when the student gets further opportunities to examine the pathophysiological reasons why patients deteriorate. Given the central role of students in taking and recording vital observations this assessment goes further than ever before to ensure that students and registered nurses adhere to the maxim "First Do No Harm". The process of ensuring patient safety starts with students having the fundamental knowledge to know how to undertake clinical skills, as incorrect technique when conducting vital observations often causes harm. When and how to act if a patient deteriorates as well as having the skills required to use equipment which provides more clinically accurate data, such as manual blood pressure auscultation. From the literature and data discussed, supportive learning requires a multi-modal approach to learning and teaching. Therefore, students must be equipped with the knowledge and skills if they are to adhere to the maxim of Primum non nocere "First do no harm".

\section{Conflicts of InTEREST Disclosure}

The authors declare that there is no conflict of interest.

\section{REFERENCES}

[1] Smith CM. Origin and use of the Primum non nocere - above all, do no harm! Journal of Clinical Pharmacology. 2005; 45(4): 371377. PMid:15778417 http://dx.doi .org/10.1177/009127000 4273680

[2] Nightingale F. Notes on Hospitals (3rd ed.) Longman, Green and Roberts: London, 1863.

[3] Clarke SP, Aiken LH. Failure to rescue. American Journal of Nursing. 2003; 103: 42-47. PMid:12544057 http://dx.doi.org/10.10 97/00000446-200301000-00020

[4] Jones S, Bottle A, Griffiths P. As assessment of 'failure to rescue' derived from routine NHS data as a nursing sensitive patient safety in- dicator for surgical in-patient care. 2011: National Nursing Research Unit: Kings College: London.

[5] Zeitz K, McCutcheon H. Observations and Vital Signs: ritual or vital for the monitoring of post-operative patients. Applied Nursing Research. 2006; 19(4): 204-211. PMid:17098158 http://dx.doi .org/10.1016/j.apnr.2005.09.005

[6] Bennett M, McVeig G. Having vital skills in practice. Nursing Standard. 2013: 27(45): 72. PMid:23923171 http://dx. doi .org/10. 7748/ns2013.07.27.45.72.s56

[7] Macintosh N, Sandall J. Failure to Rescue: problem and solutions. 2008: NIHR King's Patient Safety and Service Quality Centre Working Paper 1. Available from: http://www . academia.edu/24657 64/Failure_to_rescue_problems_and_solutions 
[8] Jansen JO, Cuthbertson BH. Detecting critical illness outside of the ICU: the role of track and trigger systems. Current Opinion in Critical Care. 2010; 16: 184-190. PMid:20305556 http://dx.doi.org/1 $0.1097 /$ MCC. 0b013e328338844e

[9] De Meester K, Verspuy M, Monsieurs KG, et al. SBAR improves nurse-physician communication and reduces unexpected death: a pre and post intervention study. Resuscitation. 2013; 84(9): 11921196. PMid:23537699 http://dx.doi.org/10.1016/j.resus citation.2013.03.016

[10] Merriman C, Westcott L. Succeed in OSCEs and Practical Exams: an essential guide for nurses. 2010: MacGraw Hill: London.

[11] Carraccio C, Englander R. The objective structured clinical examination: a step in the direction of competency based education. Archives of Paediatrics Adolescent Medicine. 2000; 154: 736-741. http://dx.doi.org/10.1001/archpedi.154.7.736

[12] NPSA Recognising and responding appropriately to early signs of deterioration in hospitalised patients. 2007: National Patient Safety Agency: London.

[13] Harden R, Gleeson FA. Assessment of clinical competence using an objective structured clinical examination (OSCE). Medical Education. 1979; 13: 41-54. PMid:763183 http://dx.doi.org/10.11 11/j.1365-2923.1979.tb00918.x

[14] Arnold RC, Walmsley AD. The use of OSCE in postgraduate education. European Journal of Dental Education. 2008; 12(3): 126130. PMid:18666892 http://dx.doi.org/10.1111/j.1600-0 $579.2008 .00469 . \mathrm{x}$

[15] Mueller J. Authentic assessment toolbox. 2012. Available from: http://jfmueller.faculty.noctrl.edu/toolbox/whatisit.htm

[16] Bloom B. Taxonomy of educational objectives: The cognitive domain. 1956: New York: Donald McKay.

[17] Cowen M, Maier P, Price G. Study skills for nursing and health care students. 2009: Essex, Pearson.

[18] Greenhalgh T, Donald A. Evidence based health care workbook: understanding research for individual and group learning. 2000: London, BMJ books.
[19] Miller GA. The magical number seven, plus or minus two: Some limits on our capacity for processing information. Psychological Review. 1956; 63(2): 81-97. http://dx.doi.org/10.1037/h0043158

[20] Artino AR. Cognitive load theory and the role of learner experience: An abbreviated review for educational practitioners. Association for the Advancement of Computing in Education Journal. 2008; 16(4): 425-439.

[21] Kesten KS. Role-Play Using SBAR Technique to Improve Observed Communication Skills in Senior Nursing Students. Journal of Nursing Education. 2011; 50: 79-87. PMid:21210611 http: //dx.doi.org/10.3928/01484834-20101230-02

[22] Lewin K. Force field in social science. 1951: New York, Harper and Row.

[23] Franklin BJ, Osborne HW. (Eds.) Research Methods: Issues and Insights. 1971: Wadsworth Publishing Company.

[24] Oppenheim A. Questionnaire Design, interviewing and Attitude Measurement. 1992: London, Pinter.

[25] Law M. Reduce, reuse, recycle: issues in the secondary use of research data. Available from: http://www. iassistdata.org/do wnloads/iqvol291law.pdf

[26] Lee RM. Unobtrusive Methods in Social Research. 2000: Buckingham: Open University Press.

[27] Booth A. Innovative Uses of the Freedom of Information Act (2000) for Research. 2009: Available from: http: //www.rin.ac.uk/our-work/researcher-development-a nd-skills/freedom-information-tool-researchers-0

[28] Morgan CL, Beerstretcher HJ. Practice size and service provision in primary care: an observational study. British Journal of General Practice. 2009; 59(560): 71-77. PMid:19275826 http://dx.doi . org/10.3399/bjgp09X419538

[29] Walsh N. So where are all of the alternative providers in primary care? British Journal of Healthcare Management. 2007; 13(2): 43-46. http://dx.doi.org/10.12968/bjhc.2007.13.2.24227

[30] Nursing and Midwifery Council. Record Keeping: guidance for nurses and midwives. 2009: Available from: http: //www.nmc-uk.org/Documents/NMC-Publication s/NMC-Record-Keeping-Guidance.pdf 